\title{
Nested Case-Control Study of Occupational Chemical Exposures and Prostate Cancer in Aerospace and Radiation Workers
}

\author{
Anusha Krishnadasan, $\mathrm{PhD}^{1}{ }^{1}$ Nola Kennedy, $\mathrm{PhD}^{2}{ }^{2}$ Yingxu Zhao, $\mathrm{PhD},{ }^{1}$ \\ Hal Morgenstern, $\mathrm{PhD}^{3}$ and Beate Ritz, MD, $\mathrm{PhD}^{1,2}$
}

\begin{abstract}
Background To date, little is known about the potential contributions of occupational exposure to chemicals to the etiology of prostate cancer. Previous studies examining associations suffered from limitations including the reliance on mortality data and inadequate exposure assessment.

Methods We conducted a nested case-control study of 362 cases and 1,805 matched controls to examine the association between occupational chemical exposures and prostate cancer incidence. Workers were employed between 1950 and 1992 at a nuclear energy and rocket engine-testing facility in Southern California. We obtained cancerincidence data from the California Cancer Registry and seven other state cancer registries. Data from company records were used to construct a job exposure matrix (JEM) for occupational exposures to hydrazine, trichloroethylene (TCE), polycyclic aromatic hydrocarbons (PAHs), benzene and mineral oil. Associations between chemical exposures and prostate cancer incidence were assessed in conditional logistic regression models.

Results With adjustment for occupational confounders, including socioeconomic status, occupational physical activity, and exposure to the other chemicals evaluated, the odds ratio for low/moderate TCE exposure was 1.3; 95\%CI $=0.8$ to 2.1, and for high TCE exposure was 2.1; $95 \% C I=1.2$ to 3.9. Furthermore, we noted a positive trend between increasing levels of TCE exposure and prostate cancer ( $P$-value for trend $=0.02$ ).

Conclusion Our results suggest that high levels of TCE exposure are associated with prostate cancer among workers in our study population. Am. J. Ind. Med. 50:383390, 2007. ๑ 2007 Wiley-Liss, Inc.
\end{abstract}

KEY WORDS: occupational chemical exposure; prostate cancer; job exposure matrix; trichloroethylene; nested case-control study

\footnotetext{
${ }^{1}$ Department of Epidemiology, School of Public Health, University of California, Los Angeles

${ }^{2}$ Department of Environmental Health Sciences, School of Public Health, University of California, Los Angeles

${ }^{3}$ Department of Epidemiology, School of Public Health, University of Michigan, Ann Arbor, Michigan

Contract grant sponsor: California Cancer Research Program; Contract grant number: 00-00781V-20218.

${ }^{*}$ Correspondence to: Anusha Krishnadasan, Department of Emergency Medicine, Olive View-UCLA Medical Center, 14445 Olive View Drive, North Annex Bldg. Rm 105, Sylmar, CA 91342.E-mail: akrishna@ucla.edu
}

Accepted 8 February 2007

DOI 10.1002/ajim.20458. Published online in Wiley InterScience

(www.interscience.wiley.com)

\section{INTRODUCTION}

It has previously been reported that occupational exposure to certain chemicals may increase prostate cancer risk [Parent and Siemiatycki, 2001]. For example, elevated risks have been reported for exposure to cadmium, polycyclic aromatic hydrocarbons (PAHs), engine emissions, asbestos, and chemicals involved in metalworking, work in the rubber industry, fire fighting, and farming and agriculture [Van der Gulden et al., 1992; Krstev et al., 1998; Parent and Siemiatycki, 2001]. However, to date there is no consensus that any of these agents cause prostate cancer partly due to 
limitations of many previous studies such as their reliance on mortality data and inadequate exposure assessment.

Occupational cohort studies that rely on mortality data for measuring outcomes [Boice et al., 2006; Brown and Delzell, 2000; Collins et al. 1999; Marsh et al., 2001; Ritz, 1999; Weston et al., 2000; Whorton et al., 1998] are limited by the fact that prostate cancer is typically a non-fatal cancer. The survival rate for prostate cancer is high $(90 \%$ in the U.S.), [Grossfield and Carroll, 2001] and the number of cancer deaths low relative to the number of incident cases. Consequently, such studies usually lack statistical power and render results inconclusive [Costantino et al., 1995]. Moreover, findings might not be an accurate reflection of etiologic factors, but may instead be related to factors associated with fatality [Demers et al., 1992].

Studies that utilize job titles or categories as a proxy for exposure to chemicals might be prone to considerable exposure misclassification and inefficiency [Checkoway et al., 1987; Elghany et al., 1990; Sharma-Wagner, 2000]. This affects registry-based studies especially, since generic job titles or industries (such as farming, metal work, etc.) often represent a great range of possible chemicals and exposure levels. Industry-based studies that can access employment records and other data sources for exposure assessment and allow the creation of a job exposure matrix (JEM) usually improve exposure assessment [Goldberg et al., 1993]; but such studies often do not have access to or are unable to collect information on potential non-occupational confounding risk factors [Dosemeci et al., 1993; Hsing et al., 1994; Krstev et al., 1998; Buxton et al., 1999; Brown and Delzell, 2000; Norman et al., 2002].

We attempted to address some of these shortcomings, by conducting a nested case-control study of prostate cancer incidence among former workers of a nuclear energy and rocket engine development and testing facility. A statewide cancer registry in California established in 1988 provided us with 12 years of prostate cancer incidence data. We were able to employ company records, retired worker interviews, and industrial hygiene review to construct an industry-based JEM and estimate exposures to selected known or suspected carcinogens commonly used at the facility. These resources were also used to assess exposure to other occupational risk factors and potential confounding factors, including physical activity levels at work and pay status as a proxy for socioeconomic status (SES). Finally, we conducted a survey among a subset of living workers to collect data on potentially confounding lifestyle factors.

\section{MATERIALS AND METHODS}

\section{Study Population}

Selection of subjects has been previously described [Ritz et al., 2000, 2006]. Briefly, subjects were selected from two worker cohorts, which were assembled in the early 1990's to study whether exposure to radiation and hydrazine were related to cancer mortality [Ritz et al., 2000; Morgenstern and Ritz, 2001]. Workers were employed between 1950 and 1993 at a rocket engine and nuclear power testing facility in Los Angeles County. The radiation cohort consisted of 4,607 workers enrolled in the company's radiation monitoring program, who were primarily involved in research and development of nuclear power systems. The aerospace cohort consisted of 6,107 workers who were involved in rocket engine development and testing. The aerospace cohort was restricted to men employed for at least two years and who started their employment before 1980. For the present prostate cancer study, all women were excluded from the radiation cohort $(\mathrm{n}=276)$. We excluded 1,410 workers from both cohorts who died before 1988 according to data from company retirement beneficiary records, the U.S. Social Security administration, California mortality records, and the U.S. National Death Index (NDI).

Eight cancer registries were searched to identify 392 cases of prostate cancer diagnosed between January 1, 1988 and December 31, 1999: 337 from California; 8 from Nevada; 12 from Arizona; 6 from Texas; 15 from Washington; 11 from Florida; 2 from Arkansas; and 1 from Oregon. Necessary approvals from Human Subjects committees in all states were obtained to access these data. Cancer registry coverage was incomplete during the followup period in four states: Texas (coverage period: 19961999), Washington (1992-1999), Arkansas (1996-1999), and Oregon (1996-1999). We were also unable to obtain cancer incidence data from other U.S. states where $11 \%$ of our workers had died during follow-up, according to NDI records.

A nested case-control study approach was chosen to make the record review necessary for exposure assessment feasible within the limits of funding for this study. Controls were randomly selected from the original cohorts, using riskset sampling. They were matched $(5: 1)$ to prostate cancer cases, on age at start date of employment ( \pm 2 years), age at diagnosis ( \pm 2 years), and which of the two cohorts they were selected from, i.e., radiation or aerospace. Thus, initially, 1,896 controls were matched to 392 prostate cancers diagnosed and identified during follow-up.

After obtaining additional information during our record review, we subsequently excluded 1) 105 workers (17 cases and 88 controls) first employed after 1980 or having worked for less than 2 years at Rocketdyne to ensure that workers from both cohorts were similar in terms of minimum years of employment; 2) two presumed male controls found to be female; and 3) fourteen cases and one control found to have received a secondary diagnosis of prostate cancer within three years of another primary cancer. The final study population consists of 362 cases and 1,805 controls. 


\section{Exposure Assessment}

Details about the JEM have been previously published [Zhao et al., 2005; Ritz et al., 2006]. Briefly, we compiled a list of known and suspected carcinogens that were regularly used at the facility, including hydrazine, trichloroethylene (TCE), benzene, mineral oil, and polycyclic aromatic hydrocarbons (PAHs). A JEM for chemical exposures was developed by our industrial hygienist (IH; N.Kennedy) and reviewed by an occupational epidemiologist (B. Ritz); both assembled data for the original cohort studies and gained knowledge of work practices at the company by interviewing company personnel and observing employees.

We extracted information about the longest job held at the company from personnel records; for $80 \%$ of the workers this was the only job held. We also extracted information for those with more than one job that either had a high potential for chemical exposures, or any job held for an equal number of years as the longest job. This second job was often a junior level position of their longest job which they had held for two or three years, e.g., a research engineer may have started employment as a research assistant, or a test engineer may have started work as a technician. There were 64 workers without job title information and we treated these workers as having been unexposed.

Using job description manuals and the knowledge gained in walk-through surveys of the facility and worker and manager interviews, our IH created an estimate of the likelihood (none, low, high), and intensity (low, medium, high) of exposure to chemicals for each job title over three periods: 1950's and 60's; 1970's; and 1980's and 90's. Ratings for each job title were performed blinded to casecontrol status of subjects. Duration of employment and the estimated intensity of chemical exposure in the longest job held were combined (i.e., multiplied) to create an exposure score for each chemical. If a worker held a job besides their longest job held $(n=293)$, this score was created for each job separately, and then added to create a cumulative exposure score for each chemical. Since workers in the radiation and aerospace cohorts were exposed to different levels of chemicals, exposure assessments for job titles common to both groups (e.g., research and test engineers) took into account the work environments.

We also created a JEM for occupational physical activity using a 5-point intensity scale for three different time periods (1950's and 60's, 1970's, and 1980's and 90's; Krishnadasan A, et al., manuscript in review). Jobs with a score of ' 3 ' or greater were classified as 'high' activity (walking with heavy and light manual work); a score of '2' represented 'moderate' activity (sitting and standing with some walking); and a score of ' 1 ' 'low' activity (mainly sitting). Pay status information obtained from company records were used to categorize workers into three SES groups: 1) professional/salaried workers, 2) non-professional/salaried workers, and 3) hourly workers.

Survey Population

We obtained address and telephone information using on-line information services for 734 workers -249 cases and 485 matched controls (using the same matching criteria as for the nested case-control study population) - all of whom were still alive in 1999. We received mailed questionnaires and/or interviewed 338 workers (140 cases and 248 controls), but were unable to obtain information from the remaining workers because of death (13\%), refusal (17\%), missing contact information (12\%), and nonresponse (11\%). In this survey, we asked subjects to describe recreational physical activity at different periods over their lifetime: ages 18-25, ages 25-44, ages 45-64, and over age 65 . We also obtained information on race, weight and height history (to calculate body mass index), smoking history, education, diabetes, family history of prostate cancer, and whether they underwent regular screening for prostate cancer.

\section{Statistical Analysis}

We employed risk set analysis; therefore, new risk sets were created by selecting all workers who were at risk for prostate cancer at the time of each case diagnosis. For all members in a riskset, exposures to chemicals were only considered up to the date of diagnosis of the case, which enabled us to address time-dependent exposures, i.e., chemicals used at the facility. Variables that we originally matched on to select the study population were entered into all models as covariates [Breslow and Day, 1980; Rothman and Greenland, 1998].

We created categories of exposure (none, low, moderate and high) for each chemical using the quartile cut point values of the cumulative exposure scores among exposed workers. The unexposed workers were considered the referent group in data analyses. Since associations were similar at low and moderate exposure levels these two categories were combined for each chemical.

Some chemical exposures were strongly correlated, e.g., $88 \%$ of workers exposed to TCE were also exposed to PAHs (Pearson correlation coefficient $(\mathrm{r})=0.82, P<0.001), 87 \%$ exposed to hydrazine were also exposed to TCE $(\mathrm{r}=0.88$, $P<0.001$ ), $92 \%$ exposed to mineral oil were also exposed to TCE ( $\mathrm{r}=0.74, P<0.001)$, and $98 \%$ exposed to benzene were also exposed to PAHs $(\mathrm{r}=0.94, P<0.001)$. Therefore, multicollinearity among the chemical exposures could result in imprecision and instability of estimates if entered into the same model.

First, we estimated odds ratios and 95\% confidence intervals for prostate cancer employing conditional logistic regression models for each chemical exposure adjusting for 
matching variables only. In addition, to account for possible mutual confounding between chemicals and other occupational risk factors, we examined the association of each chemical and prostate cancer risk adjusting for matching variables, other occupational factors (occupational physical activity and SES) and all other chemicals. We also lagged chemical exposures by 10 and 20 years to explore induction/ latency intervals between chemical exposures and prostate cancer incidence. This was achieved by excluding exposures received 10 or 20 years prior to the year of diagnosis for the case and matched controls in each risk set. Finally, we examined workers from each of the two cohorts separately, i.e., radiation and aerospace workers.

Survey Population Analysis

We intended to use the survey information to assess potential confounding due to non-work related risk factors for prostate cancer. However, the survey population of workers still alive in 1999 differed considerably from the cohort population in terms of their occupational histories and exposures suggesting selection bias. Respondents were more likely to hold professional/salaried positions (60\% vs. 52\%), experienced lower occupational physical activity levels, and were somewhat more likely to have been exposed to high levels of chemicals. Thus, we only conducted some limited analyses evaluating other non-occupational risk factors reported in the survey. In order to do so we broke up the risk sets and employed unconditional logistic regression while controlling for matching variables. We also examined the distributions of these risk factors across occupational TCE exposure levels to assess their potential for confounding.

\section{RESULTS}

The most common chemicals workers were exposed to were PAHs (39\%), followed by TCE (37\%), hydrazine (31\%), mineral oil (19\%) and benzene (13\%; Table I). Cases and controls were relatively similar in terms of duration of employment, pay status, and occupational physical activity levels. Yet, generally more cases were assigned to the highest chemical exposure levels according to our JEM.

Crude model estimates comparing workers with high levels of exposure to each chemical to unexposed workers suggest that high levels of TCE, PAHs and benzene exposure are related to prostate cancer risk (Table II). However, including all chemicals, physical activity and SES in our model resulted in a clear association for only one chemical, i.e., high TCE exposure still increased the incidence of prostate cancer more than twofold, and the association between TCE and prostate cancer appeared dose dependent $(P$-value for trend $=0.02)$. Furthermore, the TCE association increased slightly when exposures were lagged by 20 years.
Lagging exposures by 10 years did not change odds ratio estimates for all chemical exposures (results not shown). We also observed a moderate, yet imprecisely estimated association at high benzene exposure levels, yet lagging exposures by 20 years removed the association. Lagging exposures 20 years did not affect associations for other chemicals. When stratifying by cohort type, results did not change and supported our overall findings of an association between TCE exposure and prostate cancer incidence (zero lag, highest exposure level: radiation cohort OR [95\%CI]: $1.8[0.66,4.9]$ and aerospace cohort OR [95\%CI]: $1.9[0.87,4.1])$, however, due to the smaller sample size the estimates are imprecise.

Survey Population Results

Controlling only for matching variables, the following risk factors were positively associated with prostate cancer among the 338 workers who participated in the our survey: African-American race OR $[95 \% \mathrm{CI}]=3.6[0.7,19]$, obesity $(\mathrm{BMI} \geq 30) \quad \mathrm{OR}[95 \% \mathrm{CI}]=2.0[1.0,4.2]$, regular participation in prostate cancer screening OR $[95 \% \mathrm{CI}]=$ $2.4[1.2,4.8]$, and having a family history of prostate cancer $\mathrm{OR}[95 \% \mathrm{CI}]=3.5[1.7,7.0]$. Being diabetic was inversely associated with prostate cancer $\mathrm{OR}[95 \% \mathrm{CI}]=0.4[0.2,0.9]$. Obesity and participating in regular prostate cancer screening did not vary across levels of TCE exposure. Also, TCE levels did not vary greatly with race and the number of African American men among workers was very small $(n=7)$. However, workers with any occupational TCE exposure were less likely to report a family history of prostate cancer, and highly exposed workers were about twice as likely to be diabetic (Table III).

\section{DISCUSSION}

Our results suggest that workers with high TCE exposure were twice as likely to develop prostate cancer as workers without such exposure, controlling for occupational physical activity, SES, and occupational exposure to hydrazine, benzene, PAHs and mineral oil. This association was slightly stronger when exposures were lagged by 20 years, which suggests TCE exposure may be involved in the induction of prostate cancer. The increases in risk observed at high levels of exposure to benzene and PAHs in crude models mostly disappeared when we controlled for other chemicals. In fact, adjustment for TCE exposure was mostly responsible for the observed changes in estimates. The moderate association for high benzene exposure in zero lag models disappeared when exposures were lagged by 20 years. This might suggest that either benzene exposure is unrelated to prostate cancer incidence, or might act within a shorter lag or as a promoter rather than initiator of prostate cancer. However, due to the small number of benzene exposed subjects, it was not possible to investigate this association further. 
TABLE I. Descriptive Statistics of Occupational Information Derived From Company Records, California Aerospace, and Radiation Workers

\begin{tabular}{|c|c|c|c|}
\hline Occupational variables & $\begin{array}{c}\text { All workers } \\
\text { N (\%) }\end{array}$ & $\begin{array}{c}\text { Cases } \\
\text { (n=362) } \\
N(\%)\end{array}$ & $\begin{array}{c}\text { Controls } \\
\begin{array}{c}(n=1,805) \\
N(\%)\end{array}\end{array}$ \\
\hline Mean (median) duration of employment (in years) & $18(16)$ & $19(19)$ & $18(15)$ \\
\hline \multicolumn{4}{|l|}{ Hydrazine exposure level $^{\mathrm{a}}$} \\
\hline None (score $=0$ ) & $1487(69)$ & $248(69)$ & $1239(69)$ \\
\hline Low/moderate $(1<$ score $\geq 19)$ & $515(24)$ & $76(21)$ & $439(24)$ \\
\hline $\operatorname{High}($ Score $>19)$ & $165(7.6)$ & $38(11)$ & $127(7.0)$ \\
\hline \multicolumn{4}{|l|}{ TCE exposure level ${ }^{\mathrm{a}}$} \\
\hline None $($ score $=0$ ) & $1374(63)$ & $227(63)$ & $1147(64)$ \\
\hline Low/moderate $(1<$ score $\geq 16)$ & $624(29)$ & $90(25)$ & $534(30)$ \\
\hline $\operatorname{High}($ score $>16)$ & $169(7.8)$ & $45(12)$ & $124(6.9)$ \\
\hline \multicolumn{4}{|l|}{ PAH exposure level $\left.\right|^{a}$} \\
\hline None $($ score $=0$ ) & $1313(61)$ & $218(60)$ & $1095(61)$ \\
\hline Low/moderate $(1<$ score $\geq 18)$ & $661(31)$ & $96(27)$ & $565(31)$ \\
\hline High (score $>18)$ & $193(8.9)$ & $48(13)$ & $145(8.0)$ \\
\hline \multicolumn{4}{|l|}{ Benzene exposure level $^{\mathrm{a}}$} \\
\hline None (score $=0$ ) & $1884(87)$ & $320(88)$ & $1564(87)$ \\
\hline Low/moderate $(1<$ score $\geq 19)$ & $216(10)$ & $24(6.6)$ & $192(11)$ \\
\hline High (score $>19)$ & $67(3.1)$ & $18(5.0)$ & $49(2.7)$ \\
\hline \multicolumn{4}{|l|}{ Mineral oil exposure level ${ }^{a}$} \\
\hline None (score $=0$ ) & $1749(81)$ & $296(82)$ & $1453(81)$ \\
\hline Low/moderate $(1<$ score $\geq 17)$ & $316(15)$ & $46(13)$ & $270(15)$ \\
\hline High (score $>17)$ & $102(4.7)$ & $20(5.5)$ & $82(4.5)$ \\
\hline \multicolumn{4}{|l|}{ Cohort $^{\mathrm{b}}$} \\
\hline Radiation & $753(35)$ & $127(35)$ & $626(35)$ \\
\hline Aerospace & $1414(65)$ & $235(65)$ & $1179(65)$ \\
\hline \multicolumn{4}{|l|}{ Pay status/SES } \\
\hline Professional/salaried & $1107(52)$ & $193(54)$ & $914(51)$ \\
\hline Non-professional/salaried & $701(33)$ & $104(29)$ & $597(34)$ \\
\hline Hourly & $323(15)$ & $59(17)$ & $264(15)$ \\
\hline \multicolumn{4}{|l|}{ Occupational physical activity ${ }^{\mathrm{a}}$} \\
\hline Low & $904(42)$ & $148(41)$ & $756(42)$ \\
\hline Moderate & $693(32)$ & $128(35)$ & $565(31)$ \\
\hline High & $570(26)$ & $86(24)$ & $484(27)$ \\
\hline
\end{tabular}

${ }^{a}$ Scores derived from Job exposure matrices and ranges for chemicals derived from quartile cut points.

${ }^{\mathrm{b}}$ Radiation cohort were workers involved in research development of nuclear power systems and aerospace cohort were workers involved in rocket engine development and testing.

Few previous epidemiologic studies investigated associations between prostate cancer and the chemicals we evaluated. Some studies suggested elevated risks for aircraft and metal product fabricators and exposures to liquid fuel combustion products, and lubricating oils and greases [Van der Gulden et al., 1992; Aronson et al., 1996]. A cohort study of aerospace workers found the mortality rate of prostate cancer elevated among those exposed to TCE [Morgan et al., 1998; $\mathrm{RR}=1.4795 \% \mathrm{CI} 0.85$ to 2.55]. A cohort study found a slightly elevated incidence (SIR) of prostate cancer among workers exposed to TCE [Weiss,
1996]. Very few studies evaluated the potential link between hydrazine exposure and prostate cancer, and those that did were cancer mortality investigations [Morris et al., 1995; Ritz et al., 1999] yielding imprecise and inconclusive results.

While $40 \%$ of our study population was considered exposed to PAHs, we observed a weak association between exposure to PAHs and prostate cancer $(22-34 \%$ increased risk, with 95\% CI including the null value) after adjusting for exposure to other chemicals. Stronger associations have been reported in previous studies, possibly because 
TABLE II. Crude and Adjusted Conditional Logistic Regression Results for Prostate Cancer Risk by Level of Chemical Exposure Score`, California Aerospace and Radiation Workers

\begin{tabular}{|c|c|c|c|}
\hline Chemical exposure score levels* & Crude OR (95\%CI) & Adjusted OR (95\%Cl) zero laga & Adjusted OR (95\%Cl) 20 year laga \\
\hline \multicolumn{4}{|l|}{ Hydrazine } \\
\hline Unexposed & 1.0 & 1.0 & 1.0 \\
\hline Low/Moderate & $0.98(0.76,1.3)$ & $0.84(0.56,1.3)$ & $0.75(0.50,1.1)$ \\
\hline \multirow[t]{2}{*}{ High } & $1.4(0.96,2.0)$ & $0.83(0.49,1.4)$ & $0.84(0.48,1.5)$ \\
\hline & $P$ trend ${ }^{\dagger}=0.23$ & $P$ trend $=0.39$ & $P$ trend $=0.30$ \\
\hline \multicolumn{4}{|l|}{ TCE } \\
\hline Unexposed & 1.0 & 1.0 & 1.0 \\
\hline Low/Moderate & $1.0(0.82,1.3)$ & $1.3(0.81,2.1)$ & $1.3(0.81,2.1)$ \\
\hline \multirow[t]{2}{*}{ High } & $1.8(1.3,2.5)$ & $2.1(1.2,3.9)$ & $2.4(1.3,4.4)$ \\
\hline & $P$ trend $=0.01$ & $P$ trend $=0.02$ & $P$ trend $=0.01$ \\
\hline \multicolumn{4}{|l|}{ PAHs } \\
\hline Unexposed & 1.0 & 1.0 & 1.0 \\
\hline Low/Moderate & $1.0(0.77,1.2)$ & $0.93(0.61,1.4)$ & $1.0(0.69,1.6)$ \\
\hline \multirow[t]{2}{*}{ High } & $1.6(1.2,2.2)$ & $1.2(0.71,2.1)$ & $1.3(0.73,2.5)$ \\
\hline & $P$ trend $=0.05$ & $P$ trend $=0.63$ & $P$ trend $=0.43$ \\
\hline \multicolumn{4}{|l|}{ Benzene } \\
\hline Unexposed & 1.0 & 1.0 & 1.0 \\
\hline Low/Moderate & $0.73(0.51,1.1)$ & $0.84(0.52,1.4)$ & $0.86(0.55,1.3)$ \\
\hline \multirow[t]{2}{*}{ High } & $1.9(1.2,3.0)$ & $1.5(0.79,2.8)$ & $1.0(0.49,2.2)$ \\
\hline & $P$ trend $=0.74$ & $P$ trend $=0.83$ & $P$ trend $=0.74$ \\
\hline \multicolumn{4}{|l|}{ Mineral Oil } \\
\hline Unexposed & 1.0 & 1.0 & 1.0 \\
\hline Low/Moderate & $1.0(0.79,1.4)$ & $1.2(0.80,1.9)$ & $1.2(0.81,1.9)$ \\
\hline \multirow[t]{2}{*}{ High } & $1.1(0.65,1.7)$ & $0.72(0.38,1.4)$ & $0.86(0.42,1.8)$ \\
\hline & $P$ trend $=0.84$ & $P$ trend $=0.12$ & $P$ trend $=0.93$ \\
\hline
\end{tabular}

${ }^{\text {aAll }}$ estimates are adjusted for matching variables (cohort and age at diagnosis), occupational physical activity (low, high), SES (hourly and non-professional/salaried pay status), and all other chemical exposure levels.

${ }^{*}$ Scores derived from JEM.

${ }^{\dagger} P$-value for Trend.

investigators studied subjects with high exposure to PAHs in closed environments, e.g., power plant operators [Krstev et al., 1998], motor mechanics, auto and railway engineers [Seidler et al., 1998], and boiler room workers [Aronson et al., 1996]. At this facility, PAHs were mainly generated through the burning of fossil fuels for jet engines, and exposures to workers probably occurred mostly outdoors, which may explain the weak association observed. In contrast, TCE was mainly used as a solvent, such as for degreasing engines after testing operations were completed. These operations were likely to have a high potential for both dermal and inhalation exposure to TCE.

TABLE III. Comparing Distribution of Potential Confounders Across TCE Exposure Levels* (None, Low/Moderate, and High) Among Survey Controls ( $\mathrm{n}=198)$, California Aerospace and Radiation Workers

\begin{tabular}{lccc} 
Potential confounder & $\begin{array}{c}\text { No TCE exposure } \\
(\mathbf{n}=\mathbf{1 0 0}) \\
\text { No. (\%) }\end{array}$ & $\begin{array}{c}\text { Low/moderate TCE exposure } \\
\mathbf{( n = 6 7 )} \\
\text { No. (\%) }\end{array}$ & $\begin{array}{c}\text { High TCE exposure } \\
(\mathbf{n}=\mathbf{3 1}) \\
\text { No. (\%) }\end{array}$ \\
\hline African American & $0(0)$ & $1(2)$ & $1(3)$ \\
Obese $(\mathrm{BMI}>30)$ & $11(11)$ & $7(10)$ & $5(16)$ \\
Regular prostate cancer screening & $82(82)$ & $53(79)$ & $24(77)$ \\
Family history of prostate cancer & $12(12)$ & $2(3)$ & $3(10)$ \\
Diabetic & $18(18)$ & $7(10)$ & $8(26)$ \\
\hline
\end{tabular}

*Scores derived from JEM. 
A biologically plausible mechanism for the involvement of specific chemicals in prostate carcinogenesis in humans has not been established. However, some biologically-based hypotheses have been generated from the results of animal studies that experimentally induced prostate tumors; these include a hormone-mediated pathway, and the disruption of normal enzymatic activity and/or immune system function. Diesel engine emissions have been shown to induce changes in enzymatic activities in the prostate gland of animals [Seidler et al., 1998]. PAHs or other chemical constituents of diesel exhaust such as certain hydrocarbons, may also have hormonal effects with possible carcinogenic potential. In addition, the antiestrogenic effects of certain hydrocarbons, such as benzo(a)pyrene, may promote the growth of prostate cancer cells [Seidler et al., 1998]. However, the clinical importance of hormonal or other pathways for the prostate gland invoked for various chemicals, remains inadequately understood.

Although our survey population was a biased sample of our entire worker population with respect to occupational chemical exposures, well-established non-occupational risk factors, such as black race, regular screening for prostate cancer, and family history of prostate cancer were associated with prostate cancer among survey participants. We also observed a protective effect of diabetes on prostate cancer as previously reported by Zhu et al. (2004). Due to the selection bias in our survey population, we were unable to formally assess confounding due to non-occupational risk factors in regression models. However, we assessed whether these other risk factors for prostate cancer were associated with TCE exposure among control survey participants and found that this was only the case for family history of prostate cancer and being diabetic. However, since workers with high TCE exposure were more likely to have diabetes and less likely to have a family history of prostate cancer, possible confounding due to these factors would cause the TCE and prostate cancer association to be weaker than observed.

The main limitation of any JEM is misclassification of exposure, i.e., it is possible that a worker with a specific job title may not be exposed to chemicals to the same degree as other workers with the same job title. This is especially a problem for more general job titles found in our worker population, such as 'project engineer' or 'technicianmember technical staff.' However, the JEM for this study was constructed blinded to outcome status; therefore, any misclassification would likely be non-differential and result in attenuated risk estimates. Furthermore we used an industry-based JEM that is expected to have greater specificity for exposures than a JEM constructed for a general population [Goldberg et al., 1993].

Although employees worked at the company for a significant portion of their careers (average duration of employment was 18 years), some workers may have held other jobs for a longer period of time. Therefore, they could have been exposed to different levels of chemicals outside of this company. If switching to jobs with higher or lower exposure is related to prostate cancer diagnosis, this would result in biased estimates. However, workers usually stay in the same job or change to jobs with similar exposures [Sun et al., 2003]. Also, most cases were probably retired by the time they received a prostate cancer diagnosis (mean age at diagnosis: 68 years; mean age of retirement among survey participants: 63 years); thus, it is not likely that job changes were related to diagnosis.

Finally, some of the controls in our population may have been diagnosed with prostate cancer before 1988. We had information on prostate cancer diagnoses from four cancer registries that were in existence before 1988 . We found that there were only 2 previously diagnosed cases that were selected as controls in our study population (and were excluded). Therefore, we do not expect we are missing very many additional cases that occurred before 1988. However, some controls may have been diagnosed with prostate cancer between 1988 and 1999 in other states not covered by the registries from which we collected data. We used national mortality data to estimate the number of cancers we might be missing in other states, assuming that prostate cancer mortality is correlated with prostate cancer incidence, and cancer incidence rates and exposure distributions are similar for workers who moved and did not move to non-coverage states. Since only $12 \%$ of prostate cancer deaths that occurred between 1988 and 1999 in the study population were reported outside of these states, we estimate that we may be missing approximately 53 cases of prostate cancer in our two cohorts together. From among these, however, we expect to have selected inappropriately no more than 3-5 men as controls; therefore, we expect the outcome misclassification to be minimal.

In summary, our data shows that workers at the facility exposed to high levels of TCE, especially before the late 1970's, were more likely to develop prostate cancer. Furthermore, adjustment for other occupational exposures and lagging of TCE exposures strengthened the observed associations. Our survey of surviving workers suggested that lifestyle factors are unlikely to have acted as confounders of the association.

\section{ACKNOWLEDGMENTS}

We thank Kavitha Pathmarajah for help with data collection and entry, and the employees of the Rocketdyne/ Boeing Company who provided valuable information about work conducted at the facility.

\section{REFERENCES}

Aronson KJ, Siemiatycki J, Dewar R, Gerin M. 1996. Occupational risk factors for prostate cancer: Results from a case-control study in Montreal, Quebec, Canada. Am J Epid 143(4):363-373. 
Boice JD, Marano DE, Cohen SS, Mumma, MT, Blot WJ, Brill AB, Fryzek JP, Henderson BE, McLaughlin JK. 2006. Mortality among Rocketdyne workers who tested rocket engines, 1948-1999. JOEM 48(10):1070-1092.

Breslow NE, Day NE. 1980. Statistical methods in cancer researchThe analysis of case-control studies. IARC Sci Publ Volume I(32):5338

Brown DA, Delzell E. 2000. Motor vehicle manufacturing and prostate cancer. Am J Ind Med 38:59-70.

Buxton JA, Gallagher RP, Le ND, Band PR, Bert JL. 1999. Occupational risk factors for prostate cancer mortality in British Columbia, Canada. Am J Ind Med 35:82-86.

Checkoway H, DiFerdinando G, Hulka B, Mickey DD. 1987. Medical, life-style, and occupational risk factors for prostate cancer. Prostate 10:79-88.

Collins JJ, Strauss ME, Riordan SG. 1999. Mortalities of workers at the Nitro plant with exposure to 2-mercaptobenzothialzole. Occup Environ Med 56(10):667-671.

Costantino JP, Redmond CK, Bearden A. 1995. Occupationally related cancer risk among coke oven workers: 30 years of follow-up. JOEM 37(5):597-604

Demers PA, Vaughan TL, Checkoway H, Weiss NS, Heyer NJ, Rosenstock L. 1992. Cancer identification using a tumor registry versus death certificates in occupational cohort studies in the United States. Am J Epid 134:1232-1240.

Dosemeci M, Hayes RB, Vetter R, Hoover RN, Tucker M, Engin K, Unsal M, Blair A. 1993. Occupational physical activity, socioeconomic status, and risks of 15 cancer sites in Turkey. Cancer Causes Control $4: 313-321$

Elghany NA, Schumacher MC, Slattery ML, West DW, Lee JS. 1990. Occupation, cadmium exposure, and prostate cancer. Epidemiology $1: 107-115$

Goldberg M, Kromhout H, Guenel P, Fletcher AC, Gerin M, Glass DC, Heederik D, Kaupinnen T, Ponti A. 1993. Job exposure matrices in industry. Int J Epidemiol 22 (Suppl. 2):S10-S15.

Grossfeld GD, Carroll PR. 2001. Prostate cancer early detection: A clinical perspective. Epidemiol Rev 23:173-179.

Hsing AW, McLaughlin JK, Zheng W, Gao YT, Blot WJ. 1994 Occupation, physical activity, and risk of prostate cancer in Shanghai, People's republic of China. Cancer Causes Control 5:136-140.

Krstev S, Baris D, Stewart P, Hayes RB, Blair A, Dosemeci M. 1998. Risk for prostate cancer by occupation and industry: A 24-state death certificate study. Am J Ind Med 34:413-420.

Marsh BG, Youk AO, Collins JJ. 2001. Re-evaluation of lung cancer risk in the acrylonitrile cohort study of the National Cancer Institute and the National Institute for Occupational Safety and Health. Scand J Work Environ Health 27(1):5-13.

Morgan RW, Kelsh MA, Zhao K, Heringer S. 1998. Mortality of aerospace workers exposed to trichloroethylene. Epidemiology 9(4): $424-431$.
Morgenstern H, Ritz B. 2001. Effects of radiation and chemical exposures on cancer mortality among Rocketdyne workers: A review of three cohort studies. Occup Med 16:219-237.

Morris J, Densem JW, Wald NJ, Doll, R. 1995. Occupational exposure to hydrazine and subsequent risk of cancer. Occup Environ Med 52: $43-45$.

Norman A, Moradi T, Gridley G, Dosemeci M, Rydh B, Nyren O, Wolk A. 2002. Occupational physical activity and risk for prostate cancer in a nationwide cohort study in Sweden. Br J Cancer 86:70-75.

Parent M, Siemiatycki J. 2001. Occupation and prostate cancer Epidemiol Rev 23(1):138-143.

Ritz B, Morgenstern H, Froines J, Moncau J. 1999. Chemical exposures of rocket-engine test-stand personnel and cancer mortality in a cohort of aerospace workers. JOEM 41(10):903-910.

Ritz B, Morgenstern H, Crawford-Brown D, Young B. 2000. The effects of internal radiation exposure on cancer mortality in nuclear workers at Rocketdyne/Atomics International. Environ Health Perspect 108(8): $743-751$.

Ritz B, Zhao Y, Krishnadasan A, Kennedy N, Morgenstern H. 2006. Estimated effects of hydrazine exposure on cancer incidence and mortality in aerospace workers. Epidemiology 17(2):154-161.

Rothman K, Greenland S. Modern Epidemiology 1998. 2nd edition Philadelphia Lippincott-Raven Publisher

Seidler A, Heiskel H, Bickeboller R, Elsner G. 1998. Association of diesel exposure at work and prostate cancer. Scand J Work Environ Health 24(6):486-494

Sharma-Wagner S, Chokkalingam AP, Malker HSR, Stone BJ, McLaughlin JK, Hsing AW. 2000. Occupation and prostate cancer risk in Sweden. JOEM 42(5:) 517-525.

Sun Y, Taeger D, Weiland SK, Keil U, Straif K. 2003. Job titles and work areas as surrogate indicators of occupational exposure. Epidemiology $14: 361-367$.

Van der Gulden JW, Kolk JJ, Verbeek ALM. 1992. Prostate cancer and work environment 34(4):402-409.

Weiss NS. Cancer in relation to occupational exposure to trichloroethylene. 1996. Occup Environ Med 53(1):1-5

Weston TL, Aronson KJ, Siemiatycki J, Howe GR, Nadon L. 2000. Cancer mortality among males in relation to exposures assessed through a job-exposure matrix. Int J Occup Environ Health 6(3):194202.

Whorton MD, Amsel J, Mandel J. 1998. Cohort mortality study of prostate cancer among chemical workers. Am J Ind Med 33(3):293296.

Zhao Y, Krishnadasan A, Kennedy N, Morgenstern H, Ritz B. 2005. Estimated effects for solvents and mineral oils and cancer mortality and incidence. Am J Ind Med 48(4):249-258.

Zhu K, Lee IM, Sesso HD, Buring JE, Levine RS, Gaziano JM. 2004 History of diabetes mellitus and risk of prostate cancer in physicians. Am J Epid 159(10):978-982. 